\title{
Material Selection and Analysis of Oil Film Pressure for the Floating Ring Bearing of Turbocharger

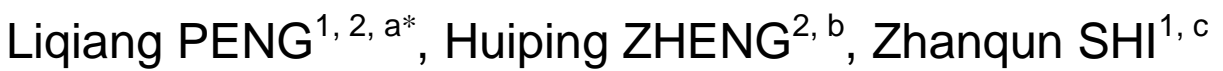

\author{
${ }^{1}$ School of Mechanical Engineering, Hebei University of Technology, Tianjin China 300130 \\ ${ }^{2}$ School of mechanical engineering, Hebei University of Science and Technology, \\ Shijiazhuang, China 050018 \\ apq200600@163.com, bhpzheng@126.com, cz_shi@hebut.edu.cn
}

Keywords: Turbocharger, Floating ring bearing, Oil film pressure, Dynamic characteristics.

\begin{abstract}
Floating ring bearing has the characteristics of simple structure, low power consumption and high efficiency. It is suitable for high speed and light load occasions. It has been widely used in high speed rotating machinery such as turbo charger, aviation engine and so on. Firstly, the materials of each component of the turbocharger rotor system are selected. Secondly, parameterized model of turbocharger floating ring bearing was established by the software DyRoBes-Beperf, when ring ratio is constant analysis of oil film pressure distribution for floating ring bearing were conducted, and eccentricity, oil film stiffness, damping variation with speed. The calculation in this paper provides some reference for the design and analysis of the turbine rotor and the floating ring bearing.
\end{abstract}

\section{Introduction}

Turbocharger is driving part of automobile engine, It play an important role for automobile energy saving, emission reduction and improve the power. At present, turbocharger commonly uses floating ring bearing as the supporting parts, its structure is shown in Fig. 1, floating ring bearing has double oil film support. It has the advantages of simple structure, long service life, good stability and so on, so it can be widely used in high speed rotating machinery.

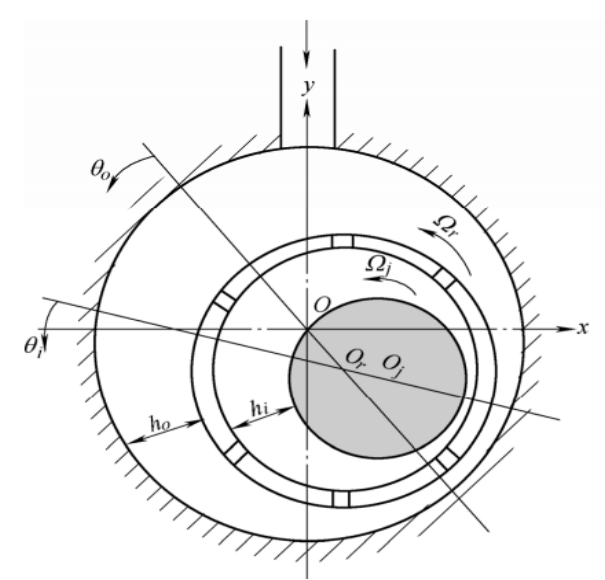

Fig. 1 Structure diagram of floating ring bearing.

So far, a lot of research on floating ring bearing dynamic characteristics parameters has been done at home and abroad: W. J. Zhang, W. Chen [1] considering floating ring and shaft neck rotary angle speed, discussed the inner and outer layers of derived in nonlinear dynamic load of oil film force analytical model, and analyzed the dynamic effect mechanism on ring ratio and whirl ratio of floating ring structure parameters at the different speed eccentric mass and viscosity of lubricating oil, and speed ratio matching system parameters sensitive to the degree of variation. S. Y. Xu, M. Yan and others [2] considering the effect of thermal effect on the ratio of the ring, and with the 
experimental basis, modified calculation formula of floating ring bearing speed ratio. H. Zhang, Z. Q. Shi [3] using finite difference method based on the mass conserving boundary condition (JFO) characterization of inner and outer oil film pressure distribution of the Reynolds equation, derived both inside and outside the oil film bearing capacity, flow rate and injection in oil film pressure oil filling quantity of expression difference, starved lubrication state of oil film pressure distribution model was built. Using MATLAB to carry on the simulation computation of floating ring bearing lubrication mechanism, analysis the static load and supply pressure of the floating ring and the shaft neck static equilibrium position, both inside and outside the oil film end discharge and differential pressure oil filling quantity, and then discuss the starved lubrication condition of Journal of static equilibrium position.

Basis on the lubricating fluid theory, considering the thermal efficiency to deal with oil film viscosity, the inner and outer bearing eccentricity change rules with the speed were calculated, when speed ratio is constant, floating ring bearing inner and outer oil film pressure ware calculated at the different speed of turbocharger rotor, the dynamics analysis of the floating ring bearing provides an important reference for research, designing of rotor system.

\section{Nonlinear Dynamic Model of Floating Ring Bearing}

Basic Model of Dynamic Lubrication of Floating Ring Bearing. For fluid lubrication problem, the general assumption of lubricating oil is incompressible, according to the equations of the Reynolods, based on the theory of short bearing model and plain bearing Reynolds equation, intima and adventitia equation of floating ring bearing have been discussed, oil film dynamic equation of floating ring bearing is get:

Outer oil film equation of floating ring:

$$
\frac{\partial}{\partial x}\left(h_{o}^{3} \frac{\partial p_{o}}{\partial x}\right)+\frac{\partial}{\partial z}\left(h_{o}^{3} \frac{\partial p_{o}}{\partial z}\right)=6 \mu_{o} U_{r} \frac{\partial h_{o}}{\partial x}
$$

Inner oil film equation of floating ring:

$$
\frac{\partial}{\partial x}\left(h_{i}^{3} \frac{\partial p_{i}}{\partial x}\right)+\frac{\partial}{\partial z}\left(h_{i}^{3} \frac{\partial p_{i}}{\partial z}\right)=6 \mu_{i}\left(U_{r}+U_{j}\right) \frac{\partial h_{i}}{\partial x}
$$

where, $\mathrm{h}$ is the oil film thickness, subscript $\mathrm{i}$ indicates the inner oil film, o shows the outer oil film; $\mathrm{U}$ is the bearing speed, subscript $r$ says floating ring, $\mathrm{j}$ indicates the Journal of the journal; $\mathrm{P}$ is the oil film pressure, o indicates the outer oil film, $i$ says the inner oil film. $\mu$ is oil film viscosity, $i$ expresses the inner oil film, and o is says the outer oil film.

The formula (1) is outer oil film pressure control equation, which shows that oil film pressure is only determined by the floating ring speed, inner oil film pressure control Eq. (2) shows that inner oil film pressure is controlled by the combined effect of the journal speed and floating ring speed.

Calculation of Ring Velocity Ratio Considering Thermal Effect. Thermal effect is an important factor of the effect to turbocharger floating ring bearing dynamic characteristics, the main parameters affected by the system thermal effect include floating ring bearing inner and outer layer oil film viscosity, inside and outside gap, and ring velocity ratio of floating ring. The formula adopted in this paper is [2]:

$$
\Omega=\frac{\Omega_{r}}{\Omega_{j}}=\frac{1}{1+\frac{\mu_{o} L_{o} D_{o}^{3}}{\mu_{i} L_{i} D_{i}^{3}} \cdot \frac{C_{i}}{C_{o}}}
$$

Type: $\Omega_{r}$ says floating ring speed, $\Omega_{j}$ indicates the shaft speed, $\mu_{i}, \mu_{o}$ respectively express the internal and external oil film viscosity; $L_{i}, L_{o}$ respectively indicate the length of the internal and external floating ring support; $C_{i}, C_{o}$ respectively say inside and outside oil film gap; $D_{i}, D_{o}$ respectively express floating ring inside and outside diameter. 


\section{Material of the Rotor System}

The impeller of the compressor is made of aluminum alloy, and the material of the rotor shaft section is alloy of $40 \mathrm{CrNi}$, and the impeller of turbine is made of the $\mathrm{K}-13$ iron and the gold. The performance parameters of these materials are shown in Table 1.

Table 1. Material Performance of the Rotor System.

\begin{tabular}{|c|c|c|c|}
\hline Name & Elastic modulus $(\mathrm{GPa})$ & Density $\left(\mathrm{kg} / \mathrm{m}^{3}\right)$ & Poisson ratio \\
\hline Compressor impeller & 72 & 2680 & 0.33 \\
\hline Turbine impeller & 176 & 8000 & 0.30 \\
\hline Shaft section & 200 & 7820 & 0.30 \\
\hline
\end{tabular}

\section{Analysis of Example}

The structural parameters of one turbocharger floating ring bearing are shown in Table 2, the bearing load is $15 \mathrm{~N}$, which direction is along the $\mathrm{Y}$ axis. Floating ring bearing wall thickness is $\mathrm{B}=2.475 \mathrm{~mm}$, using the formula (3), ring velocity ratio of floating ring bearing can be calculated to $\zeta=0.21$.

Table 2. Parameters of Floating Ring Bearing.

\begin{tabular}{ll}
\hline Project of floating ring & Value $(\mathrm{mm})$ \\
Quality $(\mathrm{kg})$ & 0.006 \\
Length $(\mathrm{mm})$ & $\mathrm{Li}=7, \mathrm{Lo}=7.2$ \\
Inner and outer diameter $(\mathrm{mm})$ & $\mathrm{Di}=7.05, \mathrm{Do}=12$ \\
Inner and outer Clearance $(\mathrm{mm})$ & $\mathrm{Ci}=0.025, \mathrm{Co}=0.045$ \\
Inner and outer viscosity $(\mathrm{Pa} \cdot \mathrm{s})$ & $\mu \mathrm{i}=0.02, \mu \mathrm{o}=0.027$ \\
\hline
\end{tabular}

The dynamic characteristics of the floating ring bearing are calculated and analyzed by using the special bearing analysis software DyRoBes-Beperf, and the structural parameters are shown in Table 2. Eccentricity variation of a floating ring bearing with the rotational speed is shown in Fig. 2, in the figure, $o_{r}, o_{j}, o_{j r}$ respectively indicate rate of outer oil film eccentric rate, bearing eccentric rate and the inner oil film eccentric. Fig. 3 shows that: the three eccentric rate values of floating ring bearing vary with bearing speed and all values decreases when the speed increase; and the eccentric rate of the inner oil film is minimum, eccentric rate value of floating ring outer oil film is maximum, and bearing eccentric rate take second place.

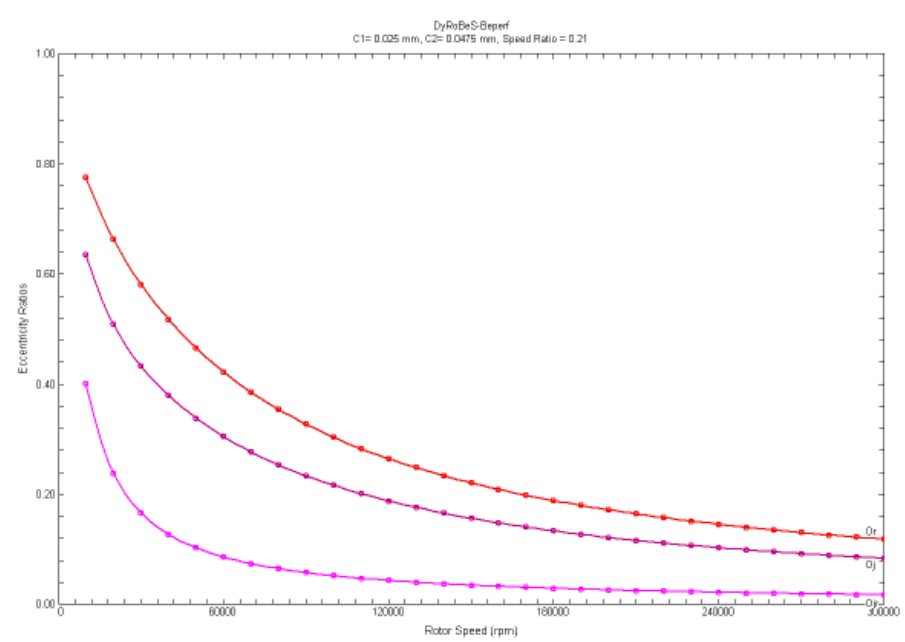

Fig. 2 Variation Law of Eccentricities of Floating Ring Bearing with Rotating Speed. 
These are centroid motion locus of a shaft neck and floating ring in Fig. 3, it can be seen from the figure that axle journal center and floating ring mass center moved to the bearing center with increasing speed, and eccentricities will decrease with increasing speed.

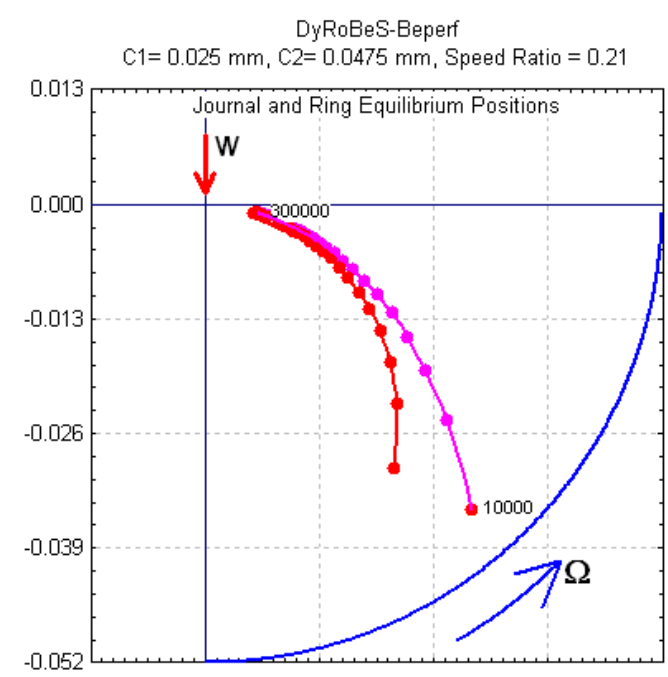

Fig. 3 Change of the track of the axis and the floating ring along with the rotational speed.

The oil film pressure of oil film bearing is composed of oil film pressure distribution, therefore, the dynamic characteristics of the bearing is directly determined by the pressure of the oil film. These are oil film pressure distribution maps of floating ring bearing at different speeds in Fig. 4. The figure shows: when bearing axis speed increases to 300 thousands per minute from 10 thousands per minute, the minimum inner oil film thickness increases to $0.0245611 \mathrm{~mm}$ from the $0.0149587 \mathrm{~mm}$ and minimum outer oil film thickness increases to $0.0418767 \mathrm{~mm}$ from 0.0106371 , inner and outer oil film thickness increases with the increase of rotational speed; maximum inner oil film pressure decreases to $330.351 \mathrm{kPa}$ from $589.385 \mathrm{kPa}$, oil outer film pressure decreases to $563.774 \mathrm{kPa}$ from $632.415 \mathrm{kPa}$, inner and outer oil film maximum value decreases with speed increases. Maximum oil film pressure changes little, when the speed value grow more than 100 thousands per minute.

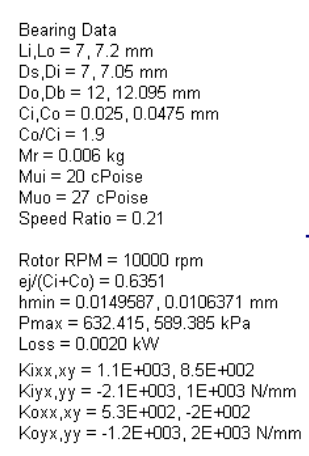

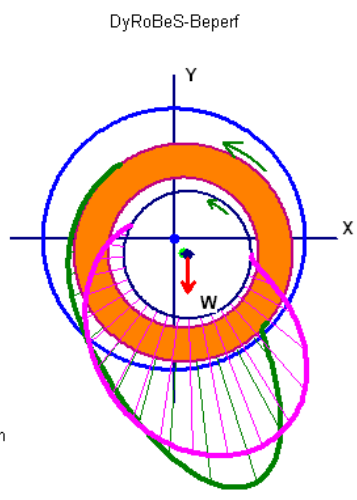

(a) $(\mathrm{n}=10000 \mathrm{r} / \mathrm{min})$
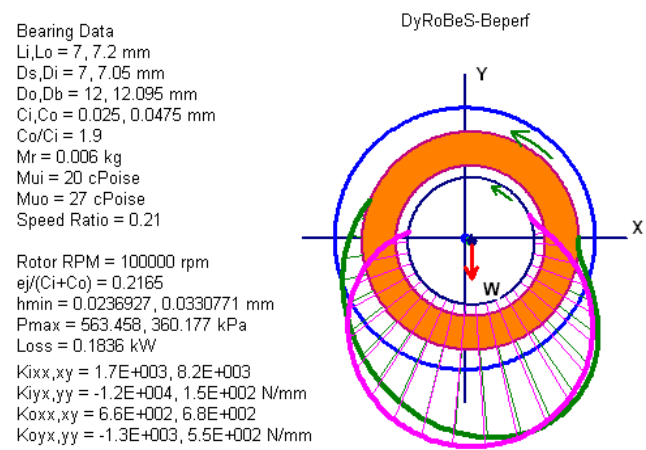

(b) $(\mathrm{n}=100000 \mathrm{r} / \mathrm{min})$ 


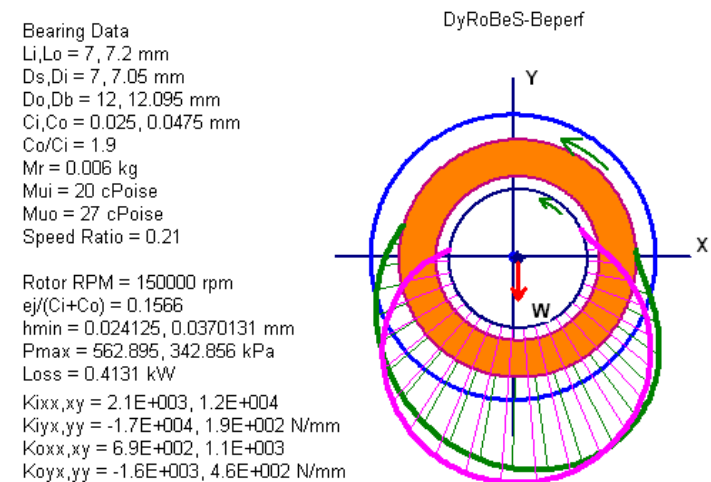

(c) $(\mathrm{n}=15000 \mathrm{r} / \mathrm{min})$

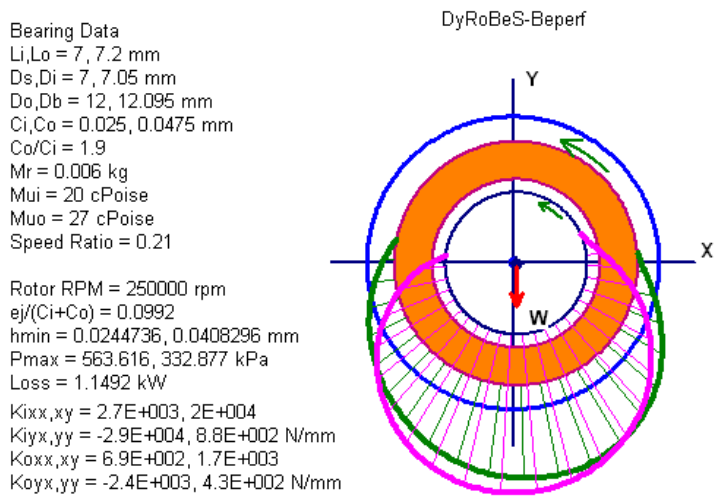

(e) $(\mathrm{n}=25000 \mathrm{r} / \mathrm{min})$

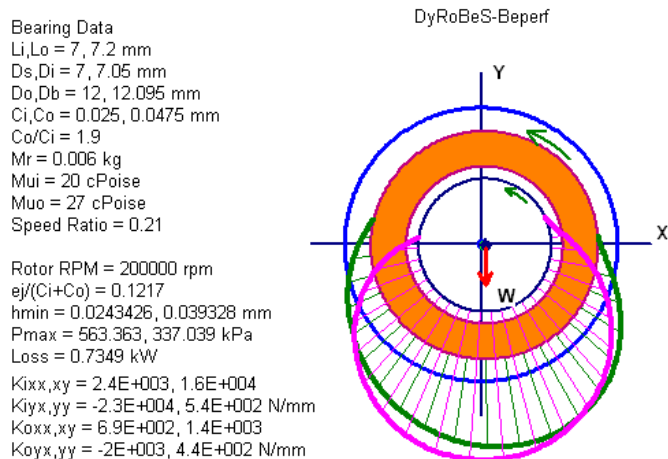

(d) $(\mathrm{n}=200000 \mathrm{r} / \mathrm{min})$

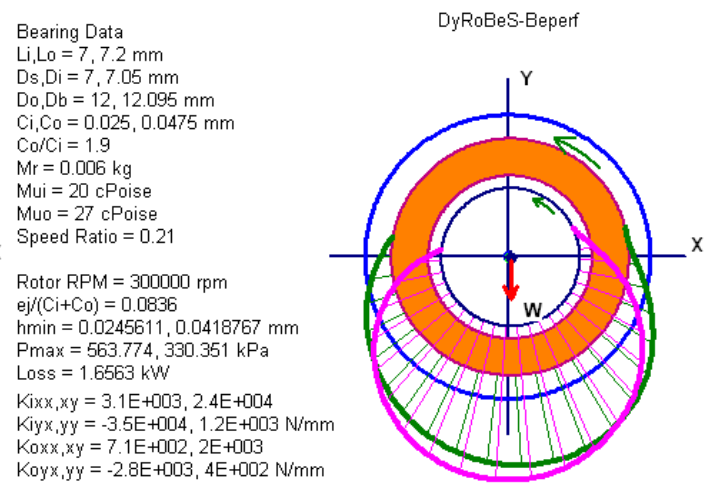

Koyx $, y y=-2.8 \mathrm{E}+003,4 \mathrm{E}+002 \mathrm{~N} / \mathrm{mm}$

(f) $(\mathrm{n}=300000 \mathrm{r} / \mathrm{min})$

Fig. 4 Oil film pressure distribution of floating ring bearing at different speeds.

\section{Conclusions}

In this paper, the dynamic model of lubrication of the floating ring bearing was established, and the ring velocity ratio calculation of floating ring has been analyzed, and the dynamic characteristics have been calculated:

(1) The eccentricities of the inner and outer oil film of floating ring bearing decrease with the increase of rotating speed, and the eccentricity of inner oil film $\left(o_{j r}\right)$ is less than that of outer oil film $\left(o_{r}\right)$.

(2) The maximum oil film pressure of the inner and outer oil film will decrease with the increase of the rotating speed, while the minimum oil film thickness increases.

\section{Acknowledgement}

The author wish thank for research funding support from the National Natural Science Foundation of China (51275150).

\section{Reference}

[1] W. J. Zhang, W. Chen, P. Li, R. X. Mei, Dynamic Effect of System Parameters for Floating Ring Bearing Ring Velocity Ratio, J. Sichuan Univ. (Engineering Science Edition), 47(3) (2015) $160-166$.

[2] S. Y. Xu, M. Yan, G. Y. Li, The Speed Ratio Calculation of Floating Ring Bearing considering thermal effect, Veh. Engine, 190(5) (2010) 18-21.

[3] H. Zhang, Z. Q. Shi, S. X. Zhang, etc. The Analysis of Floating Ring Bearing Starved Lubrication Characteristics Theory Based on the Mass Conserving Boundary Condition, J. Chin. Mech. Eng. 50(9) (2014) 100-107. 
[4] P. Zhou, Study on the Characteristics and Stability of Oil Film in the Design of Turbocharger Floating Ring Bearing, master's degree thesis of Chongqing University, 2013, 5.

[5] L. Tian, W. J. Wang, Z. J. Peng, Nonlinear effects of unbalance in the rotor-floating ring bearing system of turbochargers, Mech. Syst. Sign. Process. 34(1/2) (2013) 298-320. 